\title{
ROBOTIC UPGRADING OF POSTWAR SOCIAL DWELLING ENVELOPES
}

*K. Iturralde

University of the Basque Country

Architecture Department

Oñati Plaza,2

Donostia, Spain 20.018

(*Corresponding author: kepaiturralde@ehaeo.org)

Thomas Bock

Chair for Building Realisation and Robotics

Technische Universität München

Arcisstrasse 21

München, Germany 80333 


\title{
ROBOTIC UPGRADING OF POSTWAR SOCIAL DWELLING ENVELOPS
}

\begin{abstract}
The article discusses the possibility of automation in refurbishment processes of social dwelling built from 1950 to 1970 . These massively produced buildings were mostly designed prior to the law enforcement regarding thermal insulation or accessibility. Nowadays, many of these buildings are being retrofitted. The article focuses on the works in the external envelope. The task of renewing the whole social building stock is big and it requires a systematic process that facilitates a rapid upgrading, without neglecting the specific situation of each case. How could an automatic refurbishment process of these buildings be defined? The process should start with the data collection of the building and the creation of a 3D model using software such as BIM. The project, drafted in 3D, should facilitate the manufacture of building elements by robotics. In turn, it should be noted that during the assembly at the site, the pieces must be fixed quickly and efficiently. Is it possible to implement an automated process for the refurbishment of apartments built in the second half of the twentieth century? To approach the answer, a virtual refurbishment project is performed. The article focuses on the rehabilitation of the building envelope. Furthermore, it gives special attention to the double skin facade. It is well known that a second skin in this type of building can be an element that integrates several functions. Finally, needless to say that refurbishment of residential buildings is a need in our society. By extending its life cycle, robotic refurbishment provides more favorable socioeconomic and environmental capabilities than the sole construction of new buildings.
\end{abstract}

\section{KEYWORDS}

Renewal, façade, hanging robot, double facade

\section{INTRODUCTION}

There are several universal problems in the European apartments built during the postwar era. First, it's quite common that the insulation of the facades is insufficient. This makes the energy consumption bigger than in the cases of properly insulated facades. Many of those buildings were built with the available services, materials and installations during the postwar period. The owners have added new facilities and services in the façade. Adding services in the facade is not always a satisfactory solution. It is typical to see gas tubes, telecom wires etc on those building facades. Besides, the apartments sometimes lack sufficient space for storage and it is common to double the use of the terrace or balcony as storage space-
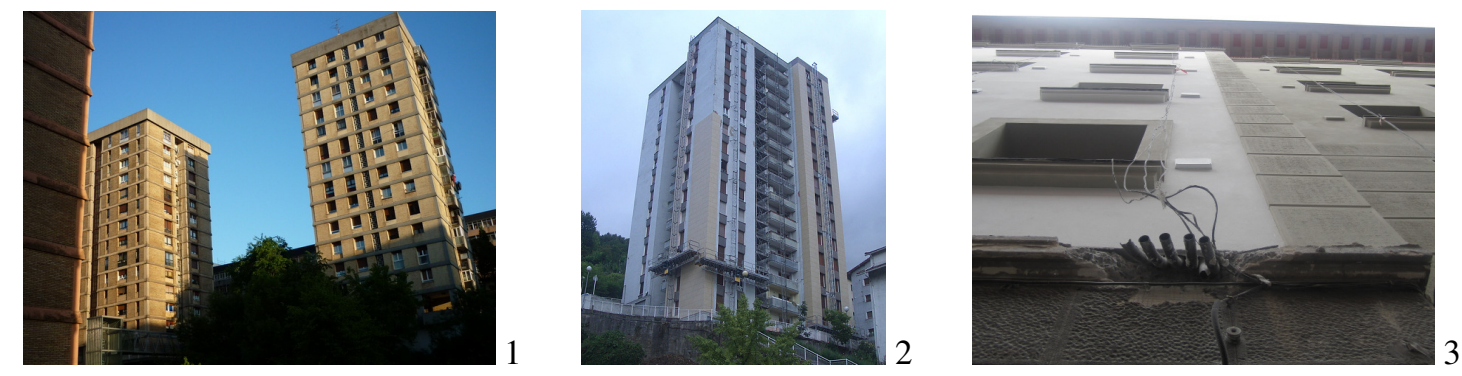

Figure 1: typical apartment building erected during the 1.960 decade.

Figure 2: renewal and external insulation of a facade using a crane.

Figure 3: final result of a "external thermal insulation composite systems" with embedded installations.

The residential buildings and surrounding areas are frequently stigmatized. it is well known the problems that occurred on the so called "banlieu" of Paris in France some years ago. In the UK, they are referred to as "council estates". 
In some cases, the first architectural design may have some interest (Etxepare, 2011). Nevertheless, most don't have any artistic or design relevance. Besides, they have suffered many alterations and recovering the original situation may not be affordable.

All of the above means that the buildings' facades require an upgrade on many levels. They need a renewal for their new uses. But those refurbishment processes are not totally efficient and they are the cause of many discomforting situations. Renewal or refurbishment processes are annoying due to noise and dirtiness. Besides, scaffolding is placed during months in front of the window, cancelling off the views one may have and reducing the privacy whenever a worker is in front of one's window.

It is a fact that a renewed facade could ameliorate the existing situation. But to tear down the existing facade and building a brand new one could be unviable in many cases. Technically and logistically it would be very difficult to pull down the entire facade and make a new one, unless you evacuate the apartments for one year's period. The problem is when the building is not owned by a housing association, and when the property is atomized among many small private owners. The decisions and the logistics make the situation non viable. This can be a tough problem, especially in some contexts. It differs from one country to another, but in some cases, for instance in Spain, those apartments are owned by their inhabitants. And normally the owner lives in the apartment permanently. Evacuating the entire building could create a big dwelling problem because the inhabitants should be relocated.

Adding a 2 meter wide double facade can be a solution when there is sufficient space in front of the building. What about if the building faces a narrow street? For those cases the layer should be much narrower and it should be anchored to the existing building.

The maintenance of the building facade should be taken into account in the design. Dismountable elements should be used in order to predict difficult situations. Nowadays facades are commonly refurbished adding exterior insulating layers to the existing one. It is quite common to use the so called "External thermal insulation composite systems". For this case, a crane or scaffolding is needed. It is basically a manual process, which consist of spreading different kind of mortars and anchoring an insulation based on foam. Material is cut and placed entirely by hand. It can take a lot of time and if the installation is not correct, humidity problems could appear.
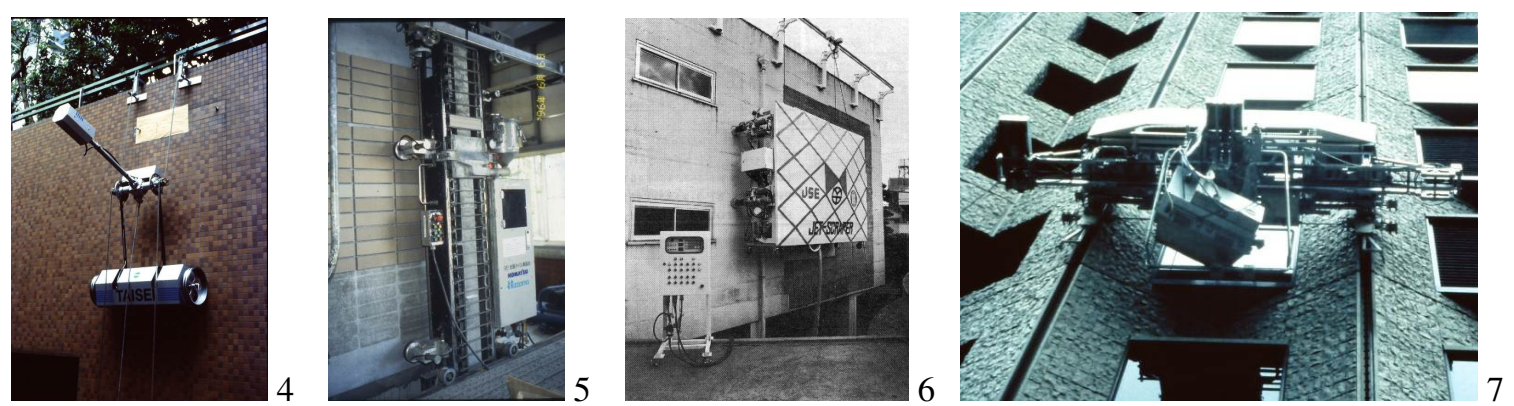

Figure 4: Facade inspection Robot Taisei

Figure 5: Facade Tile de-installation/installation robot

Figure 6: Façade delaminating Robot by Takenaka

Figure 7: Façade Painting Robot byTaisei

All Copyrights by Thomas Bock, TU Munich.

A more mechanized example is adding a "Ventilated facades system". On those cases, material is normally prefabricated. But module size may not be adjustable to the needs of the existing facade. So in this case too, manipulation of the material is also required. Even more, this system is more rigid than the one before, so multiple details and finishing have to be created due to the existing facade's peculiarities. It must be mentioned that even though the image or shape seems more technical, the maintenance of this 
ventilated facade can be complicated. For instance, it could be difficult to dismantle, especially if adhesives are used.

The existing technology is permitting better performances. New measurement techniques and an industrial robotic fabrication can provide an accurate prefab element for the facade. However, the assembly process still requires onsite manpower.

The solutions they offer may not be the specific solution for the case we are addressing in this article (Bock, 2007), but they can be used as inspiring models for further developments. Probably, none of the robots suits for the real purpose of this research. But it is good to know the existing technology in order to develop new robots that will operate new tasks.

\section{MOTIVATION}

Any solution to add an exterior layer to an existing facade, are nowadays assembled mostly manually. Workers place the elements on site using scaffoldings or special cranes. This is no precisely the best situation.

There are some tasks that have to be solved. The scaffolding system is required because of the manual assembly on site. This manual assembly and its subsequent scaffolding should be avoided. There are some reasons:

-Risks should be prevented. Scaffolding IS A structural element based on the existing street ground. The safety requirements of these structures are various (product homologation, a specific project for each case). But still, too many accidents happen and worker and even people walking close to them have had fatal injuries.

-The duration of the works is normally quite slow. Their average is $0.7 \mathrm{sq}$ meters per worker hour.

-The scaffolding expense can be up to $20 \%$ of the final cost of the facade refurbishment. If the scaffolding is avoided, a better and cheaper solution can be adopted with the same price.

In order to avoid this all, robotic assembly is needed. If there is less manipulation of the material on site, risks and problems can be prevented. We already know that automated refurbishment is more efficient than manual one (Iturralde, 2012). It is time to implement robotics on the process.

\section{RESEARCH QUESTION and PURPOSE}

Could a robotic crane operate in a facade refurbishment? Which tasks will be operated by this crane? There are many objectives that have to be covered. A prefab technical layer should be added to the facade. This new layer should improve the thermal capacity of the facade. Some of the times, the aesthetic of the building should be improved too. Many of the buildings present a deteriorated or at least a substantially modified appearance. It must seek an integration of the elements that have been added in the facades of the buildings, such as heaters, cooling systems, cupboards in the balcony, or clothes lines. The new facade elements should be "technical" meaning that the element has to be previously mechanized and prepared to host the different services. The added technical elements must have embedded the tubes for the installations in the facade. Those installations have to be searchable, let's say, every floor. Rigid insulation panels may be used, but a ventilated chamber should be needed, not to keep humidity between layers. A double facade is a solution that should be taken into account. many of the afore mentioned problems could be resolved by applying these solutions.

All of the processes should be fast and accurate. The prefab elements should be assembled rapidly. Measurements must be made constantly before and during the assembly process. 
First, the checking of the current façade's characteristics. Detecting level variations that are not obvious to the naked eye would be very important.

The elements should have some looseness in order to get fixed in its proper place. The constantly made measurements would be needed to check if the elements are properly placed or not. If during the placement a mistake would be made, the measurement should detect it and a new restructuration of the elements would be required.
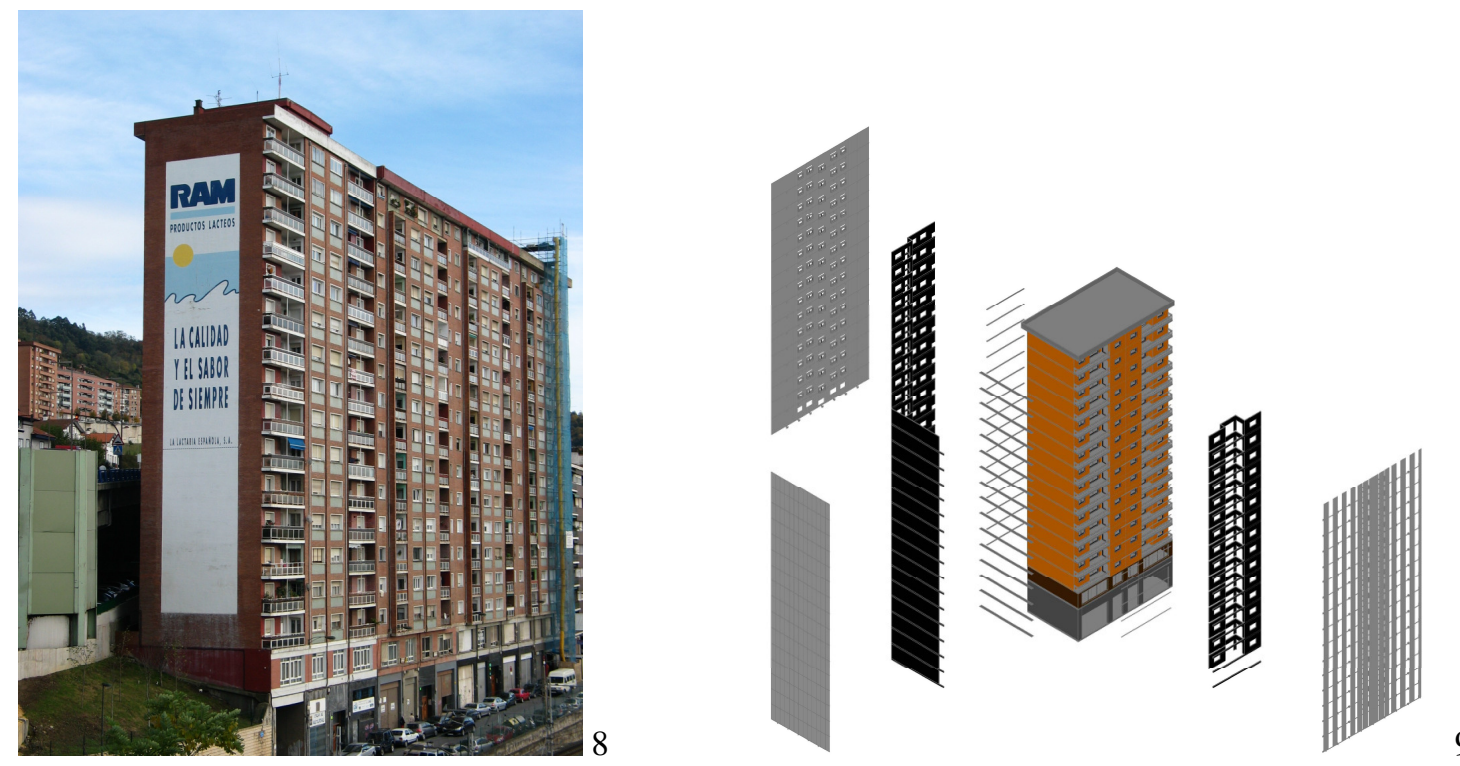

Figure 8: Case study, existing building.

Figure 9: Layers of the prefab system which need to be assembled by a robot in site.

Images by Kepa Iturralde

Somehow, a "just in time" customized element will be prepared. This could be more flexible if we work with little companies instead of big production lines.

The robot's and the prefab elements' design should be interdependent. The robot will need some characteristics that will condition the facade's element and vice versa. The facade element should not just imitate the nowadays solutions for the facades, but instead, it should be fitted to the robot and the assembly process.

In order not to overload the existing structure and facade, the robotic machinery and the facade elements should be as light as possible. On the other hand, the new renewal system should be dismountable and it should facilitate the maintenance of both the facade elements and the installations.

There are several approaches for getting an optimal system. A robot hanging from the top of the building would probably need a flat roof for its proper installation. An overhead crane robot could be operable in very little buildings, or in buildings with no traffic in its surroundings. A jointed-arm robot would probably need very stable guides either in the lower floor or either in the facade. A telescopic robot could not work if the building is more than 9 metres high.

The system should be as universal as possible. It seems that a Multipurpose Self Climbing Robot could cover the issues presented before. Let's say it could be like a "caterpillar-shaped" robot. The robot should upload the elements, place them in its proper situation and anchor them to the existing facade. There will be a problem when the facade has many overhangs, balconies and similar. A large window can 
also be a problem, because the self climbing robot may find some difficulties to fasten. The robot should be capable to cover those surfaces.

In order to anchor the elements to the existing facade, the robot has to drill or make holes. Those very same holes could be used for hanging the robot. All the elements, including the robot, should be as light as possible, in order not to overload the facade.

The majority of the publicly funded residential blocks are usually geometrically simple. Orthogonal geometry is mainly used and the facade can be considered as a planar. This fact is important in order to pre-design a specific robot to operate in that situation. In order to ameliorate the simplicity of the operations, a Cartesian Coordinate Robot would probably work in a better situation.

All the pathologies related to the spalling of the concrete, would not be treated in this article, it is a task that should be analyzed in another context.

To summarize, it must be stated that the goals of the proposed "Multipurpose Self Climbing Robot" are divided in two main areas:

-First Upgrading of the existing facade. Basically, it will consist in overlapping an additional layer with both insulation and finishing elements. This layer will be used as a facade pathologies protection. There has to be considered the choice for an energy production elements, such as Photovoltaic elements.

-Future maintenance of the added layer. Each element should be supervised every certain period, and repaired when needed. The very same robot could be used for the future maintenance. And when needed, the elements could be removed. This could be interesting if we want to make an improvement on the facade. For instance, let's say the owners would like to add photovoltaic panels. The standard facade panel should be already prepared to install new equipment. This way, the facade could be customized once and again.

\section{CASE STUDY}

A sixteen story apartment building has been analyzed. This building is located in a very dense urban area in Bilbao. A narrow robot type has been predesigned, or there has been an approximation about hot the robot should be. This robot has to be narrow in order to adapt it to the variety of buildings' special geometry. This adaptability to different kind of geometries could make the system more universal.

Those facades were commonly fabricated using brick as a base element. The facades were normally placed in the concrete floor slab. It can be affirmed that the facade is stable enough for anchoring a exterior layer. But security measures should be taken. Anchoring all elements to the structure would mean that the elements have to be at least three meters high. Working with such high elements is not possible all the times. It could be more operable to work with shorter interconnected elements, and the anchoring to the structure could be made once in three elements. 


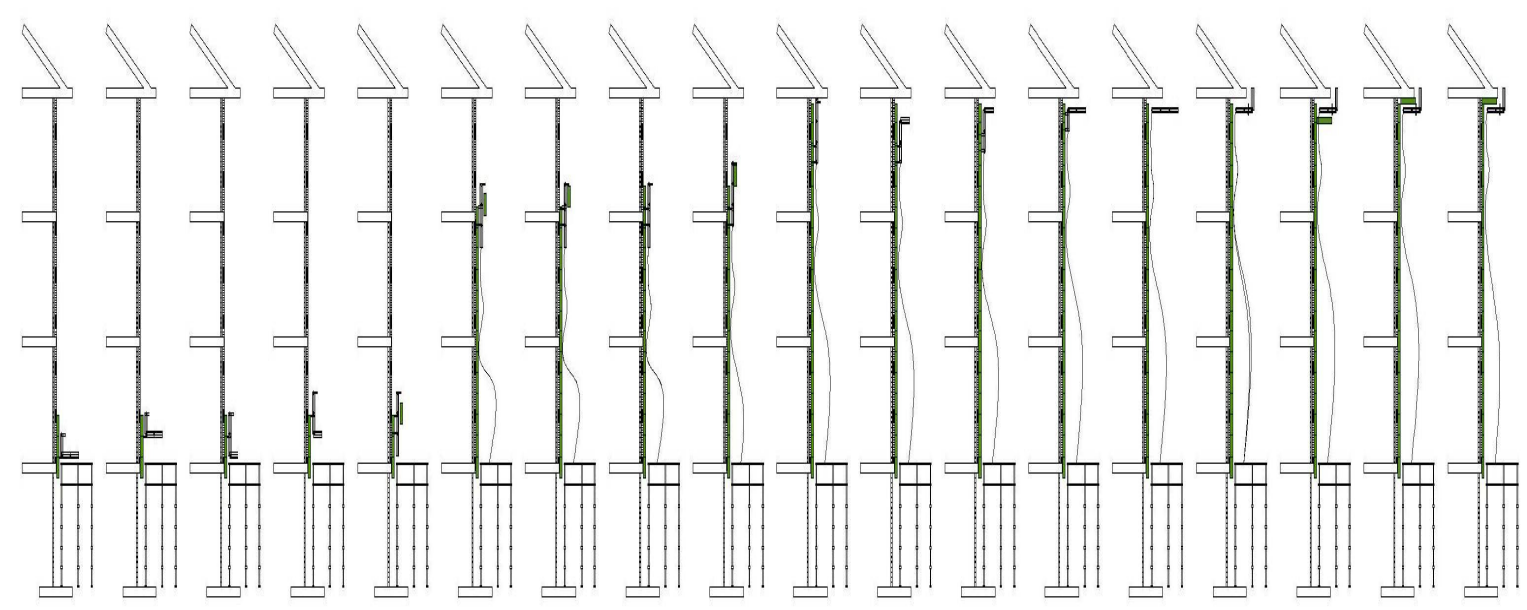

Figure 10: Assembly process sequence of the proposed system. Different cross sections of the façade are shown. The robot climbs using hydraulic system. A platform will be needed at street level. Image by Kepa Iturralde

A pre-design has been made. It is not completed yet and will require bigger definition. The robot is based in a three piece frame. Each frame can rotate from the adjacent one in order to climb the different balconies, terraces and other horizontal elements. Each frame has a different tool. The upper frame is the one for making holes. The medium frame places the facade element and the lower frame is the one that anchors the element to the existing facade. The robot will perform and anchor the elements in vertical rows.

The robot should have protections to prevent dust and particles being fallen during the assembly process. The ideal situation would be a net that could follow the self climbing robot.

Building process could start with an overall measurement. This measurement should be used for the preliminary design. Scaffolding on the ground floor will probably be needed, in order to install the robot. When first floor elements are produced on the factory, the robot could start assembling them on site. The robot would operate assembling facade elements in vertical rows or stripes. Once the first element is placed and anchored, the robot could start climbing.

Elements should be clipped or at least one to another, so they could keep up for a short period of time before they are definitely anchored. It has been said before, but the robot should first locate the structural slab and then anchor the panel to the structure.

The dimensions of the robot's frame should be adjustable or at least changeable. The size will depend in each case. The windows' and balconies' dimensions will determine the robot's frame height. The standard width of the robot's frame could be one meter. 

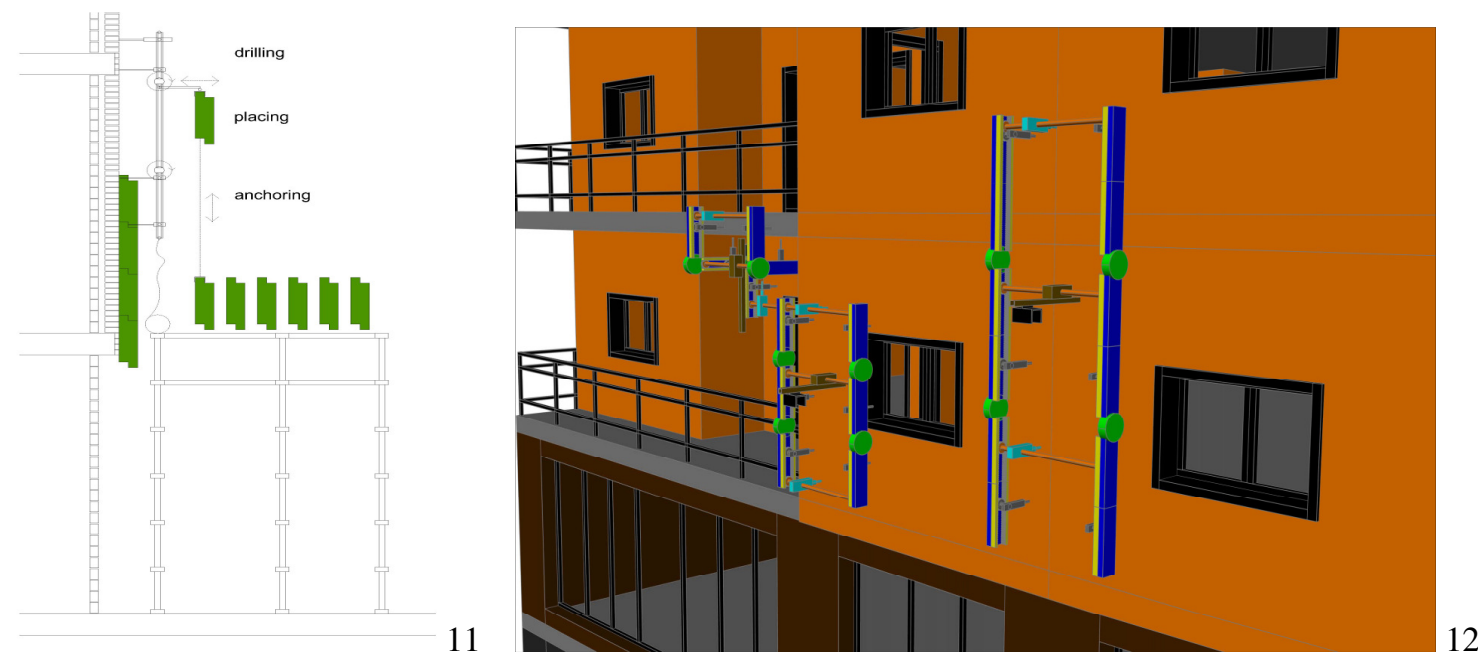

Figure 11: Assembly process scheme. Cross section of the façade. The elements are first stored on the underground platform. Then, they are uploaded and anchored to the existing façade.

Figure 12: The robot's performance view. It could be possible for the robot to fold in order to adjust to balconies.Images by Kepa Iturralde

The facade elements have been pre-designed with the proportional accuracy the robot is capable to offer, which means that the joints have vital importance. But if we design elements with wide joints, the insulation will have some gaps and the interior heat will find some leaks to reach outside. So the facade elements have to be designed with considerable flaps. Therefore, it may be difficult to obtain totally straight lines and planes. But that could be solved with constant measurement.

\section{CONCLUSION}

The research is in a development phase. But some conclusions can be affirmed. One is that maintenance of the buildings is an important matter. All the buildings built till now need a renewal in many cases. This system is only usable when the building has certain characteristics. The existing facade has to be stable and rigid enough in order to anchor some other elements. This system could not be applicable when the facade is a curtain wall facade, for instance.

The robot will operate more easily when we have a flat surface: when there are many balconies for instance, the robot is obliged to contort constantly, which probably would weaken the efficiency of the system. Could IT be better to design another robot for operating on balconies and terraces? That is a question to solve on the next step.

In order to approach the economic viability of the project, a consideration of three different levels of robotics within the very same constructive system will be made. A competitive system should be adaptable to different technology contexts. In other words, it could be reasonable to offer different robotic levels.

\section{ACKNOWLEDGEMENTS}

This research is financed by the Department of Education, Universities and Research of the Basque Government, and it has been held within the Architecture Department of the University of the Basque Country and the Chair for Building Realisation and Robotics of the Technical University Munich.

\section{REFERENCES}


Bock, T. (2007). Construction Robotics. Autonomous Robots Journal, Volume 22, Number 3, pp. 201-209, Springer Science + Business Media USA

Bock, T., Linner, T., Lee, S. (2009). Integrated Industrialization Approach for lean Off-/On -site Building Production and Resource Circulation. 7th World Conference on Sustainable Manufacturing, India

Etxepare, L., (2011) Residential Architecture and developmentalism: a place and two contexts. Structural Studies, Repairs and Maintenance of Heritage Architecture XII, ISBN:978-1-84564-526-7, p. 247-255, WIT Press

Iturralde, k. (2012). Parámetros de eficiencia en el proceso de rehabilitación de edificios: ¿es necesario un acercamiento a la automatización?. Congreso Nacional de Medio Ambiente. Madrid.

Iturralde, k. (2012). Acercamiento a la rehabilitación automatizada de edificios construidos durante la posguerra. Ekihiria kongresua. Donostia. 